\title{
Inhibition of Salmonella Enterica and Listeria Monocytogenes in Tofu by Activated Plastic Films
}

\author{
Pilar Martínez Viedma ${ }^{1}$, Maria José Grande Burgos ${ }^{1}$, Rubén Pérez Pulido ${ }^{1}$, \\ Belén Soriano $^{2}$, Antonio Gálvez ${ }^{1 *}$, Rosario Lucas ${ }^{1}$ \\ ${ }^{1}$ Department of Health Sciences, University of Jaen, 23071-Jaén, Spain. \\ ${ }^{2}$ ANDALTEC, Centro Tecnológico del Plástico; Martos, Jaén, Spain \\ I*agalvez@ujaen.es
}

\begin{abstract}
Transmission of food borne pathogens through the food chain is a matter of concern. In the present study, tofu sausage slices were used as model for testing the antimicrobial activity of low-density polyethylene (LDPE) films surface-activated with tyrosol singly or in combination with p-hydroxybenzoic acid or a bacteriocin preparation from Enterococcus faecalis. Tofu slices challenged with cocktails of Listeria monocytogenes and Salmonella enterica strains were vacuum packaged in LDPE films activated with antimicrobials and stored at $10^{\circ} \mathrm{C}$ for one month. Best results against the two foodborne pathogens tested were obtained when tyrosol (1.5\%) was used in combination with p-hydroxybenzoic acid (0.5\%). Results from the present study highlight the potential of tyrosol for development of active packaging with antibacterial activity.
\end{abstract}

Keywords: Active packaging; Tyrosol; Bacteriocin; Listeria; Salmonella.

\section{INTRODUCTION}

Tofu (soybean curd) is a popular food in Asian countries. Its consumption has been increasing in Western countries in recent years, especially by people with health concerns. Tofu is considered a healthy part of a well-balanced diet, as it is low in calories and rich in protein, iron, calcium, magnesium, and group B vitamins [1]. Usually, packaged tofu is sold in supermarkets, where it is normally found refrigerated $\left(4-10^{\circ} \mathrm{C}\right)$. In Western countries, packaged tofu is also sold in other formats such as sausages for vegetarian consumers. Unpackaged tofu is sold only in open markets, typically by independent vendors who usually display the product under conditions prone to microbial contamination [2,3]. Transmission of food borne pathogens through the food chain is a matter of concern. A recent study reported the presence of Salmonella spp. in 7\% of unpackaged tofu samples in Bangkok [4]. Several incidents of tofu recalled due to Listeria monocytogenes contamination were also reported $[5,6]$.

The application of films or coatings activated with antimicrobial substances is an attractive approach to avoid transmission of food borne pathogens through the food chain. A large variety of materials, ranging from plastic films to coating solutions based on cellulose, pectin, starch, alginate, chitosan, or proteins have been tested against food borne pathogens in different food systems [7-10]. The activated materials allow a gradual release of antimicrobial compounds into the food surface and at the same time act as a barrier against cross contamination of the packaged or coated food product. Natural antimicrobial compounds (such as essential oils or bacteriocins) are good candidates for preparation of activated films or coatings since they have a good acceptance by the consumers [11, 12]. Films based on methylcellulose or hydroxymethylcellulose activated with the bacteriocin nisin achieved a decrease in viable counts of Listeria in refrigerated tofu that was dependent on the bacteriocin concentration applied [13]. Yet, we have found no other reports in the scientific literature on application of activated films for preservation of tofu.

Antimicrobial compounds found in essential oils have the advantage over bacteriocins of being naturally active on both gram-positive and gram-negative bacteria [11]. Tyrosol is a phenolic compound resulting from hydrolysis of the olive fruit main bitter compound, oleuropein [14-16], and is found in byproducts from table olives and olive oil industry. The aim of the present study was to determine the efficacy of plastic films activated with tyrosol (an antimicrobial compound naturally 
found in olives) singly or in combination with p-hydroxybenzoic acid against Salmonella enterica and Listeria monocytogenes on sliced tofu sausages stored under temperature abuse conditions.

\section{MATERIALS AND MethodS}

\subsection{Bacterial Strains}

Listeria monocytogenes strains CECT 4032, CECT 911, CECT 936, and CECT 940, and Salmonella enterica strains CECT 915, CECT 916, CECT 4000, and CECT 4300 were supplied by the Spanish Type Culture Collection (CECT, Burjasot, Valencia, Spain). Strains were cultivated overnight at 37 ${ }^{\circ} \mathrm{C}$ on trypticase soy broth (TSB, Scharlab, Barcelona, Spain). For preparation of inocula, overnight cultures were diluted one-hundred fold in sterile saline solution. Aliquots $(1 \mathrm{ml}$ each) of the dilutions obtained for each strain were mixed together in a single test tube to prepare the cocktails of Listeria and Salmonella strains. Enterococus faecium strain VMJ53 was isolated from fresh produce. This strain produced a bacteriocin with strong anti-Listeria activity. Enterococcus faecalis S-47 was used as a bacteriocin-sensitive test strain.

\subsection{Preparation of Activated Plastic Films}

The antimicrobials tyrosol and $p$-hydroxybenzoic acid were supplied by Sigma-Aldrich (Madrid, Spain). Low density polyethylene (LDPE) films were supplied by Andaltec (Martos, Jaen, Spain).

The bacteriocin producer strain E. faecium VMJ53 was inoculated (4\%, vol/vol) in phosphatebuffered BHI broth ( $\mathrm{pH} 7.2,1$ liter) overnight. After removal of cells by centrifugation (3,500 x $g$ for $30 \mathrm{~min}$ ), the bacteriocin from supernatant was recovered by ammonium sulfate precipitation at $70 \%$ saturation while being kept under refrigeration for $18 \mathrm{~h}$. Precipitates were collected by centrifugation $(4,500 \times \mathrm{g}$ for $30 \mathrm{~min})$ and resuspended in $20 \mathrm{ml}$ phosphate buffer saline (PBS). The obtained bacteriocin concentrate was dialysed overnight using 2,000 molecular weight cut-off benzoylated dialysis tubing (SigmaAldrich, Madrid) and filtered through $0.22 \mu \mathrm{m}$ pore size low protein binding filters (Millex GV; Millipore Corp., Belford, MA, USA) under sterile conditions. The final bacteriocin preparation was serially diluted in sterile saline solution, and the titre of bacteriocin in units of activity $(\mathrm{U})$ was determined by the spot test on phosphate buffered BHA seeded with the indicator strain E. faecalis $\mathrm{S}-47$.

For surface activation with antimicrobials, films were placed on top of a sterile glass plate $(10 \times 10$ $\mathrm{cm})$. Then, $1 \mathrm{ml}$ of the antimicrobial solution to be tested was deposited on the surface of the film and spread uniformly by using a sterile $5 \mathrm{ml}$ plastic pipette. The coated films were allowed to dry for $2 \mathrm{~h}$ in a biosafety cabinet (Telstar, Madrid, Spain). Polyethylene films $(10 \times 10 \mathrm{~cm})$ surface-activated with solutions containing $2.5 \%$ tyrosol or a combination of $1.5 \%$ tyrosol plus $0.5 \%$-hydroxybenzoic acid were used to prepare plastic bags. The bacteriocin concentrate from strain VMJ53 (VMJ53) was tested at 200 and $400 \mathrm{U} / \mathrm{ml}$ singly or in combination with $2.5 \%$ tyrosol.

\subsection{Assay of Activated Plastic Films on Sliced Tofu Sausages}

Tofu sausages were purchased at a local supermarket. The sausages were sliced $(1.5 \mathrm{~cm}$ diameter by $0.3 \mathrm{~cm}$ height) with a sterile knife under aseptic conditions and surface-inoculated on one side with 10 $\mu \mathrm{l}$ of the cocktails of L. monocytogenes or S. enterica strains prepared as described above. Controls were inoculated with $10 \mu \mathrm{l}$ sterile saline solution. Tofu slices were allowed to dry at room temperature in a biosafety cabinet for $30 \mathrm{~min}$ before they were vacuum packaged in the activated plastic bags (three slices per bag). Two independent replicates (each one of them in duplicate) were prepared. Foods were stored for 7 days at $10{ }^{\circ} \mathrm{C}$ in a Peltier-refrigerated incubator (Memmert $\mathrm{GmbH}$, Schwabach, Germany). At desired incubation times, bags were removed and the food content was homogenized with $10 \mathrm{ml}$ buffered peptone water. The resulting homogenates were serially diluted in sterile saline solution and plated in triplicate on PALCAM agar with added supplement (Scharlab) for determination of Listeria and brilliant green agar (Scharlab) for determination of Salmonella. The average number of colonies obtained after $24-48 \mathrm{~h}$ incubation of the plates at $37{ }^{\circ} \mathrm{C}$ was used to calculate the viable cell concentration (expressed as $\log _{10}$ colony forming units (CFU)/g).

\subsection{Statistical Analysis}

The average data \pm standard deviations from replicates were determined with Excel programme (Microsoft Corp., USA). A paired $t$-test was performed at the $95 \%$ confidence interval in order to determine the statistical significance of data (Statgraphics Plus version 5.1, Statistical Graphics Corp, USA). 


\section{RESULTS AND DISCUSSION}

The antibacterial activity of films coated with antimicrobials is shown in Table 1. L. monocytogenes was able to grow in the refrigerated tofu slices. A significant increase in viable cell counts of $2 \log$ cycles was noticed by day 7 of storage, and viable counts were close to $8 \log$ cycles by day 15 . A previous study [17] reported that L. monocytogenes was able to grow in the three types of refrigerated tofu products tested (plain tofu, flavored tofu, and soft pudding tofu). After storage treatment for 24 days at $4-7^{\circ} \mathrm{C}$, L. monocytogenes reached 7.1-7.9 log CFU/g in the samples [17].

Salmonella enterica cells were able to grow slowly in the tofu slices stored at $10{ }^{\circ} \mathrm{C}$. Growth was noticed after 7 days of storage, reaching viable cell concentrations that were 3.5 logs higher after 15 days compared to time 0. We found no previous studies on growth of Salmonella enterica in tofu. While this bacterium has a much more limited capacity to grow under refrigerated storage compared to $L$. monocytogenes, one study showed that $S$. enterica could reach high cell concentrations (of about $6 \log \mathrm{CFU} / \mathrm{g}$ ) in egg yolk after storage for 7 days at $10^{\circ} \mathrm{C}$ [18]. These results agree with data obtained in the present study with tofu and outline the risk of accidental cross contamination of tofu with this foodborne pathogen.

The use of films or coatings activated with antimicrobials is a practical approach to control bacterial proliferation while at the same time preventing cross-contamination with foodborne pathogens [7]. Results from the present study showed that polyethylene films coated with $2.5 \%$ tyrosol not only inhibited the proliferation of the cocktail of L. monocytogenes strains in tofu slices, but also decreased the numbers of viable cells during storage (Table 1). However, inactivation of the listeriae occurred slowly, and viable counts only decreased below detectable levels after 30 days of storage. This could be attributed to a slow diffusion of the tyrosol molecules from the coating into the food matrix. Combining tyrosol with $p$-hydroxybenzoic acid improved inactivation of the listeriae. The decrease in viable cell counts was noticed from day 3 of storage, reducing viable counts below detectable levels by day 15. The bacteriocin-activated films did not decrease viable cell counts, but instead delayed growth of the listeriae (Table 1). This was noticed mostly at day 7 of storage, where viable counts in the samples coated with the bacteriocin-activated film were significantly lower $(P<0.05)$ compared to controls. However, differences in viable counts between the two bacteriocin concentrations tested were not statistically significant $(P>0.05)$. The combinations of bacteriocin and tyrosol increased anti-Listeria activity to some extent. Best results were obtained for the highest bacteriocin concentration tested, since viable counts for the combined treatment were significantly lower $(P<$ 0.05 ) compared to the single tyrosol treatment at days 7 and 15 of storage.

Films activated with tyrosol inhibited growth of the cocktail of Salmonella strains tested. However, viable cell counts still remained above detectable levels during storage (Table 1). As in the case of Listeria, the combination of tyrosol and p-hydroxybenzoic acid was also more effective against Salmonella, reducing viable cell counts below detectable levels by day 30 of storage. Viable Salmonella counts obtained for samples coated with bacteriocin-activated films were not statistically different $(P>0.05)$ compared to control samples, indicating that the bacteriocin preparation had no effect. This was expected, since the bacteriocin preparation used had no activity on Gram-negative bacteria in preliminary tests. Bacteriocin activity may be potentiated when tested in combination with other antimicrobials, especially those that alter the bacterial outer membrane permeability [12]. However, when the bacteriocin preparation was tested in combination with $2.5 \%$ tyrosol, viable cell counts were not statistically different $(P>0.05)$ compared to the single tyrosol coating.

There are scarce reports in the scientific literature about the use of activated coatings for preservation of tofu. A previous study showed that methylcellulose and hydroxypropylmethylcellulose films activated with the bacteriocin nisin showed a concentration-dependent anti-listerial activity in tofu refrigerated at $5{ }^{\circ} \mathrm{C}$ for 30 days [13]. The study concluded that nisin film for packaging tofu has the potential to overcome the problems associated with the growth and survival of L. monocytogenes and the chances of secondary contamination of opened packages in household refrigerators. According to results from the present study, the combination of tyrosol and $p$-hydroxybenzoic acid was the most effective both against $L$. monocytogenes and $S$. enterica. The combination of tyrosol and bacteriocin also seems to be potentially useful for control of L. monocytogenes. Tyrosol has the advantage of being abundant in natural products such as by-products from the olive oil industry, and is also a cheap compound compared to other phenolic antimicrobials. 
Pilar Martínez Viedma et al.

Table1. Survival of foodborne pathogens in slices prepared from tofu sausages vacuum-packaged in polyethylene films coated with antimicrobials, during storage at $10^{\circ} \mathrm{C}$.

\begin{tabular}{|c|c|c|c|c|c|}
\hline \multirow[t]{2}{*}{ Treatment conditions } & \multicolumn{5}{|c|}{ Viable counts ( $\log _{10}$ CFU/mg) during storage time (days) } \\
\hline & $\mathbf{0}$ & $\mathbf{3}$ & 7 & 15 & $\mathbf{3 0}$ \\
\hline \multicolumn{6}{|l|}{ Listeria monocytogenes } \\
\hline Control & $3.68 \pm 0.21$ & $3.60 \pm 0.34$ & $5.64 \pm 0.27$ & $7.87 \pm 0.23$ & $8.23 \pm 0.28$ \\
\hline Tyrosol $(2.5 \%)$ & $3.67 \pm 0.17$ & $2.44 \pm 0.37$ & $3.16 \pm 0.36^{*}$ & $2.89 \pm 0.44 *$ & $<1.00$ \\
\hline $\begin{array}{c}\text { Tyrosol }(1.5 \%)+\text { PHB } \\
(0.5 \%)\end{array}$ & $3.64 \pm 0.27$ & $1.60 \pm 0.42 *$ & $1.30 \pm 0.23 * * *$ & $<1.00$ & $<1.00$ \\
\hline VMJ53 (200 U/ml) & $3.55 \pm 0.19$ & $3.14 \pm 0.12$ & $3.74 \pm 0.27 *$ & $6.97 \pm 0.35$ & $7.97 \pm 0.44$ \\
\hline VMJ53 (400 U/ml) & $3.47 \pm 0.22$ & $3.07 \pm 0.34$ & $3.47 \pm 0.44^{*}$ & $6.84 \pm 0.56$ & $7.94 \pm 0.27$ \\
\hline $\begin{array}{c}\text { Tyrosol }(2.5 \%)+\text { VMJ53 } \\
(200 \mathrm{U} / \mathrm{ml})\end{array}$ & $3.27 \pm 0.27$ & $2.14 \pm 0.23$ & $2.24 \pm 0.37^{*}$ & $2.14 \pm 0.37^{*}$ & $<1.00$ \\
\hline $\begin{array}{c}\text { Tyrosol }(2.5 \%)+\text { VMJ53 } \\
(400 \mathrm{U} / \mathrm{ml})\end{array}$ & $3.14 \pm 0.23$ & $2.01 \pm 0.34 *$ & $1.77 \pm 0.34 *, * *$ & $\begin{array}{c}1.27 \pm \\
0.33 *, * * \\
\end{array}$ & $<1.00$ \\
\hline \multicolumn{6}{|l|}{ Salmonella enterica } \\
\hline Control & $3.97 \pm 0.23$ & $3.20 \pm 0.12$ & $4.77 \pm 0.37$ & $7.48 \pm 0.37$ & $8.15 \pm 0.12$ \\
\hline Tyrosol $(2.5 \%)$ & $3.96 \pm 0.42$ & $2.72 \pm 0.49$ & $3.20 \pm 0.16^{*}$ & $2.69 \pm 0.27 *$ & $2.23 \pm 0.34^{*}$ \\
\hline $\begin{array}{c}\text { Tyrosol }(1.5 \%)+\text { PHB } \\
(0.5 \%)\end{array}$ & $3.94 \pm 0.34$ & $2.43 \pm 0.15^{*}$ & $2.78 \pm 0.32 *$ & $2.27 \pm 0.25^{*}$ & $<1.00$ \\
\hline VMJ53 (200 U/ml) & $3.95 \pm 0.17$ & $3.24 \pm 0.27$ & $4.67 \pm 0.44$ & $7.27 \pm 0.47$ & $8.02 \pm 0.22$ \\
\hline VMJ53 (400 U/ml) & $3.98 \pm 0.25$ & $3.22 \pm 0.17$ & $4.56 \pm 0.34$ & $7.34 \pm 0.27$ & $8.11 \pm 0.18$ \\
\hline $\begin{array}{c}\text { Tyrosol }(2.5 \%)+\text { VMJ53 } \\
(200 \mathrm{U} / \mathrm{ml})\end{array}$ & $3.90 \pm 0.22$ & $2.77 \pm 0.34$ & $3.24 \pm 0.23 *$ & $2.67 \pm 0.24^{*}$ & $2.17 \pm 0.44^{*}$ \\
\hline $\begin{array}{c}\text { Tyrosol }(2.5 \%)+\text { VMJ53 } \\
(400 \mathrm{U} / \mathrm{ml})\end{array}$ & $3.91 \pm 0.34$ & $2.56 \pm 0.44$ & $3.17 \pm 0.21^{*}$ & $2.44 \pm 0.37 *$ & $2.11 \pm 0.27 *$ \\
\hline
\end{tabular}

PHB, $p$-hydroxybenzoic acid.

$\mathrm{U}$, bacteriocin units.

VMJ53, bacteriocin preparation from strain VMJ53.

* Counts were significantly lower $(P<0.05)$ compared to untreated controls.

** Counts were significantly lower $(P<0.05)$ compared to the single tyrosol treatment.

\section{Conclusion}

Results from the present study highlight the potential of tyrosol as a natural preservative for development of activated coatings, singly or in combination with other antimicrobials.

\section{ACKNOWLEDGMENTS}

This work was supported by grant PI_57013 (Junta de Andalucía).

\section{REFERENCES}

[1] Prestamo G. and Fontecha J., High pressure treatment on the tofu fatty acids and acylglycerols content. Innovat. Food Sci. Emerg. Tech. 8, 188-191 (2007).

[2] Asharaf H.R., White M. and Klubek B., Microbiology survey of tofu sold in a rural Illinois county, J. Food Protect. 62, 1050-1053 (1999).

[3] Tuitemwong K. and Fung D.Y.C., Microbiological study of tofu, J. Food Protect. 54, 212-216, (1991).

[4] Ananchaipattana C., Hosotani Y., Kawasaki S., Pongswat S., Latiful B.M., Isobe S. and Inatsu Y. Bacterial Contamination of Soybean Curd (Tofu) Sold in Thailand, Food Sci. Technol. Res. 18 (6), $843-848$ (2012).

[5] Associated Press, Possible contaminant prompts firm to recall tofu, San Francisco Examiner. B7 (9 February 1992).

[6] News Desk, Soybean Sprouts and Tofu Recalled for Listeria, Food Safety News (September 3, 2012) (http://www.foodsafetynews.com/2012/09/soybean-sprouts-and-tofu-recalled-for-listeria/).

[7] Appendini P. and Hotchkiss J.H., Review of antimicrobial food packaging, Inno. Food Sci. Emerg. Tech. 3, 113-126 (2002). 
[8] Atarés L. and Chiralt A., Essential oils as additives in biodegradable films and coatings for active food packaging, Trends Food Sci. Technol. 48, 51-62 (2016).

[9] Soares N.F.F., Pires A.C., Camilloto G.P., Santiago-Silva P., Espitia P.J.P. and Silva W.A., Recent patents on active packaging for food application, Recent Pat. Food Nutr. Agricult. 1, 171-178 (2009).

[10] Sung S.-Y., Sin L.T., Tee T.-T., Bee S.-T., Rahmatb A.R., Rahman W.A.W.A., Tan A.-C. and Vikhraman M., Antimicrobial agents for food packaging applications, Trends Food Sci. Tech. 33, 110-123 (2013).

[11] Burt S., Essential oils: their antibacterial properties and potential applications in foods--a review, Int. J. Food Microbiol. 94, 223-253 (2004).

[12] Galvez A., Lucas R., Pérez-Pulido R. and Grande-Burgos M.J., Food Biopreservation, (Hartel, R.W., ed.), Springer, New York (2014).

[13] Cha D.S., Chen J., Park H.J. and Chinnan M.S., Inhibition of Listeria monocytogenes in tofu by use of a polyethylene film with cellulosic dilution containing nisin, Int. J. Food Sci. Tech. 38(4), 499 - 503 (2003).

[14] Charoenprasert S. and Mitchell, A., Factors influencing phenolic compounds in table olives (Olea europaea), J. Agric. Food Chem. 60(29), 7081-7095 (2012).

[15] Amiot M.J., Fleuriet, A. and Macheix, J.J., Importance and evolution of phenolic compounds in olive during growth and maturation, J. Agric. Food Chem. 34(5), 823-826 (1996).

[16] García A., Brenes M., García P., Romero C. and Garrido A., Phenolic content of commercial olive oils, Eur. Food Res. Tech. 216(6), 520-525 (2003).

[17] Liu J.-G., Lin T.-S. and Lin W.-Y., Evaluating the growth of Listeria monocytogenes that has been inoculated into tofu containing background microflora, Food Cont. 21(12),1764-1768 (2010).

[18] Schoeni J.L., Glass K.A., McDermott J.L. and Wong A.C., Growth and penetration of Salmonella enteritidis, Salmonella heidelberg and Salmonella typhimurium in eggs, Int. J. Food Microbiol. 24(3), 385-396 (1995). 